\title{
Transitions in Latent Classes of Sexual Risk Behavior Among Young Injection Drug Users Following HIV Prevention Intervention
}

\author{
Mary Ellen Mackesy-Amiti • Lawrence J. Ouellet • \\ Lorna Finnegan · Holly Hagan · Elizabeth Golub • \\ Mary Latka · Karla Wagner · Richard S. Garfein
}

Published online: 22 August 2013

(C) The Author(s) 2013. This article is published with open access at Springerlink.com

\begin{abstract}
We analyzed data from a large randomized $\mathrm{HIV} / \mathrm{HCV}$ prevention intervention trial with young injection drug users (IDUs). Using categorical latent variable analysis, we identified distinct classes of sexual behavior for men and women. We conducted a latent transition analysis to test the effect of the intervention on transitions from higher to lower risk classes. Men who were in a highrisk class at baseline who received the intervention were $86 \%$ more likely to be in a low-risk class at follow-up compared to those in the control group $(p=0.025)$. Highrisk intervention participants were significantly more likely to transition to the class characterized by unprotected sex with a main partner only, while low-risk intervention participants were significantly less likely to transition to that class. No intervention effect was detected on the sexual risk behavior of women, or of men who at baseline were having unprotected sex with a main partner only.
\end{abstract}

Electronic supplementary material The online version of this article (doi:10.1007/s10461-013-0601-2) contains supplementary material, which is available to authorized users.

M. E. Mackesy-Amiti $(\bowtie) \cdot$ L. J. Ouellet

Division of Epidemiology and Biostatistics, School of Public Health, Community Outreach Intervention Projects, University of Illinois at Chicago, 1603 W. Taylor St., MC 923, Chicago, IL 60612, USA

e-mail: mmamiti@uic.edu

L. Finnegan

Department of Health Systems Science, College of Nursing,

University of Illinois at Chicago, Chicago, IL, USA

H. Hagan

Center for Drug Use and HIV Research, National Development and Research Institutes, New York, NY, USA
Resumen Analizamos los datos de un ensayo grade de intervención aleatorizado de prevención del VIH/VHC con jóvenes usuarios de drogas inyectables (UDI), Utilizando el análisis de variable latente categórico, se identificaron distintas clases de comportamiento sexual para hombres y mujeres. Se realizó un análisis de transición latente para probar el efecto de la intervención sobre las transiciones de alto riesgo a las clases de menor riesgo. Los hombres que estaban en una clase de alto riesgo al inicio del estudio que recibieron la intervención eran $86 \%$ más propensos a estar en una clase de bajo riesgo durante el seguimiento en comparación con los del grupo control $(p=0.025)$. Participantes en la intervención de alto riesgo tuvieron significativamente más probabilidades de transición a la clase que se caracteriza por relaciones sexuales sin protección con sólo una pareja principal, mientras que los participantes de intervención de bajo riesgo tuvieron significativamente menos probabilidades de transición a esa clase. Ningún efecto de la intervención fue detectado en el comportamiento de riesgo sexual de las mujeres o de los hombres que al inicio del estudio estaban teniendo relaciones sexuales sin protección con una pareja principal solamente.

E. Golub

Bloomberg School of Public Health, Johns Hopkins University, Baltimore, MD, USA

M. Latka

The Aurum Institute, Johannesburg, South Africa

K. Wagner · R. S. Garfein

Division of Global Public Health, School of Medicine,

University of California, San Diego, CA, USA 
Keywords HIV - Prevention - Injection drug use · Sexual risk behavior $\cdot$ Latent class analysis

\section{Introduction}

As HIV prevention efforts have achieved significant reductions in syringe-sharing among injection drug users (IDUs), attention has turned to the importance of addressing sexual transmission of HIV in this population [1-9]. High-risk behavior including exchange sex $[10,11]$ and anal sex [12-16] is associated with increased HIV transmission among IDUs, and is a potential bridge to non-IDU populations [17-20]. However, interventions with IDUs have often been less effective in reducing sexual risk behavior than injection risk behavior [21, 22].

The Third Collaborative Injection Drug Users Study (CIDUS-III) Drug Users Intervention Trial (DUIT), conducted from 2002 through 2005 in five cities, is the largest randomized HIV prevention intervention trial with young IDUs in the US to date. This study compared a peer education intervention (PEI) with a time-matched, attention control group receiving standard counseling and testing. The DUIT enhanced intervention demonstrated an overall greater decrease in injection-related HIV risk behavior compared to the control [23, 24]; however, it did not appear to have any greater effect on sexual risk behavior than the control.

The measures used for sexual risk behavior in that analysis were numbers of unprotected sex acts, including total number, and broken down by sex act (vaginal or anal) and partner type (main, other steady, casual/sex trade). However, sexual risk behavior is multi-dimensional, and is comprised of various combinations of behaviors (i.e., oral sex, anal sex, vaginal sex), partner types (i.e., casual, steady, exchange), and use of preventive measures (i.e., condom use). Participants exhibit different combinations of risk behaviors, and interventions may affect patterns of behavior in ways that one-dimensional measures do not capture. We conducted a secondary analysis of sexual risk behavior outcomes in the DUIT data to test the effect of the intervention on transitions from higher to lower risk classes at follow-up. To capture the multi-dimensional aspects of sexual risk behavior, we used latent class analysis to identify distinct classes of sexual risk among men and women. We then used latent transition analysis to investigate the effects of the intervention within each of these classes.

\section{Methods}

\section{Study Design}

We analyzed existing CIDUS-III/DUIT data collected between May 2002 and January 2004 from participants who were recruited in five US cities: Baltimore, MD; Chicago, IL; Los Angeles, CA; New York City, NY; and Seattle, WA. Details of the study objectives, design and methodology have been described elsewhere [25, 26]. Participants were eligible for the trial if they reported injecting illicit drugs in the past 6 months, intended to reside in their recruitment city for at least the next 12 months, spoke English, were between 15 and 30 years old, and tested antibody-negative for HIV and HCV at baseline $(N=2,062)$. Eligible participants who attended the post-test counseling session $(N=1,564)$ were invited to participate in the trial. Individuals who consented to participate in the trial $(N=854)$ were randomly assigned to either the PEI, or a video-discussion control group. Participants in both conditions attended six group sessions over a three-week period. All participants attended at least the first session; attendance at each of the remaining sessions was reasonably high and similar across trial arms (average $77 \%$ for PEI, $78 \%$ for control). Participants were compensated for time and travel after each visit, according to local guidelines- $\$ 20-40$ for behavioral assessment interviews, $\$ 10-15$ for each test result visit, and $\$ 20-25$ for each intervention session attended (with four sites offering a $\$ 40$ bonus for attending all six sessions).

PEI participants were informed that the purpose of the intervention was to train them to be peer educators who could help in the fight against AIDS and hepatitis in their communities. Talking to others about HIV and HCV prevention, in a pro-social role of peer educator, was expected to motivate behavior change in the educators [26]. In the first four sessions, participants learned what it meant to be a peer educator and were given tools appropriate to this role. The first two sessions focused on injection-related risk and the third and fourth sessions focused on sexual risk behavior. The format included videos; interactive discussions; exercises in skills building, role playing, and practice; and other factors such as offering community resources, information, and tools (e.g., condoms) at every session. In the fifth session, participants were given an opportunity to practice sharing risk-reduction information in a community setting, for example, by engaging in supervised peer outreach or staffing an information table at a community center or health fair. These experiences were followed by debriefing and feedback from the intervention facilitator in a community setting. The sixth session consisted of a group debriefing about the community-based peer education session, followed by a goal-setting activity.

The control condition consisted of watching videos followed by facilitated discussion for an equivalent amount of time as the PEI sessions. Videos addressing social and health issues were chosen to be of interest to the target population, yet devoid of specific HIV/HCV risk-reduction content. 
At baseline and follow-up visits, participants completed a behavioral assessment using audio computer-assisted selfinterview (ACASI) technology to minimize socially desirable responding. Retention rates for the three- and six-month follow-up visits were 64 and $76 \%$, respectively, with $83 \%$ of the sample $(N=712)$ completing at least one follow-up interview. The most common reasons for loss to follow-up were entering drug treatment (32\%), moving out of the area $(27 \%)$, and incarceration (15\%). It was previously reported that loss to follow-up was unrelated to trial arm assignment or targeted risk behaviors [25]. Institutional review boards at the CDC and all collaborating institutions approved the study protocol, and all individuals provided written, informed consent to participate in the study.

\section{Measures}

\section{Sociodemographic Measures}

Respondents provided information on sociodemographic characteristics, including sex, age, race/ethnicity, homelessness, incarceration, and sources of income (legal and illegal).

\section{Sexual Risk Behavior}

Participants were asked about their sexual activities in the previous three months, including numbers of steady and casual partners, exchanging sex for money or drugs, condom use during vaginal, anal, and oral sex with steady and casual partners, and condom use during exchange sex (see Table 1).

\section{Analysis}

Beginning with a set of 16 variables for men, and 10 variables for women, we conducted exploratory latent class analyses with the baseline data of participants who were invited to participate in the trial (unpublished data). We explored models with two to seven classes using all measures, and systematically eliminated variables and levels of variables that did not distinguish between classes, tested categorical variables derived from count measures, and combined variables that were highly collinear. Table 1 shows the initial candidate measures, and the final selected measures for men and women. Out of 16 candidate measures of male sexual risk behavior, we selected 10 for inclusion, and out of 10 candidate measures of female sexual risk behavior, we selected 7 for inclusion. The initial

Table 1 Candidate measures and final selected measures for latent class analysis

\begin{tabular}{|c|c|c|}
\hline \multirow[t]{2}{*}{ Initial candidate measures } & \multicolumn{2}{|l|}{ Selected measures } \\
\hline & Male & Female \\
\hline Number of steady female sex partners & Number of female sex partners (none, $1,>1$ ) & NA \\
\hline Number of casual female sex partners & & NA \\
\hline Number of steady male sex partners & Any male sex partner & Multiple male sex partners (vs. 0 or 1 ) \\
\hline Number of casual male sex partners & & Number of casual sex partners (none, $1,>1$ ) \\
\hline Gave money or drugs in exchange for sex & Not included & NA \\
\hline Received money or drugs in exchange for sex & Included as is & Included as is \\
\hline $\begin{array}{l}\text { Condom use with sex trade partners ( } 5 \text { point } \\
\text { ordinal scale) }\end{array}$ & Any unprotected trade sex & Any unprotected trade sex \\
\hline Any unprotected vaginal sex with main partners & Included as is & Included as is \\
\hline $\begin{array}{l}\text { Any unprotected heterosexual anal sex with main } \\
\text { partner }\end{array}$ & Included as is & Included as is \\
\hline $\begin{array}{l}\text { Any unprotected vaginal sex with other steady } \\
\text { partners }\end{array}$ & $\begin{array}{l}\text { Any unprotected vaginal sex with non-main } \\
\text { partner }\end{array}$ & $\begin{array}{l}\text { Any unprotected vaginal or anal sex with } \\
\text { non-main partner }\end{array}$ \\
\hline \multicolumn{3}{|l|}{ Any unprotected vaginal sex with casual partners } \\
\hline $\begin{array}{l}\text { Any unprotected heterosexual anal sex with other } \\
\text { steady partners }\end{array}$ & $\begin{array}{l}\text { Any unprotected heterosexual anal sex with } \\
\text { non-main partner }\end{array}$ & \\
\hline \multicolumn{3}{|l|}{$\begin{array}{l}\text { Any unprotected heterosexual anal sex with } \\
\text { casual partners }\end{array}$} \\
\hline $\begin{array}{l}\text { Any unprotected anal sex with main male partner } \\
\text { (MSM) }\end{array}$ & Included as is & NA \\
\hline $\begin{array}{l}\text { Any unprotected anal sex with other steady male } \\
\text { partners (MSM) }\end{array}$ & $\begin{array}{l}\text { Any unprotected anal sex with non-main } \\
\text { partner (MSM) }\end{array}$ & NA \\
\hline $\begin{array}{l}\text { Any unprotected anal sex with casual male } \\
\text { partners (MSM) }\end{array}$ & & NA \\
\hline
\end{tabular}


analyses indicated that for both men and women we could expect to extract at least three and not more than six classes.

Consistent with previous analyses of these data [23], the main analysis used data from the 712 participants who completed at least one follow-up interview. We conducted latent class analyses of sexual risk behaviors separately for men and women using Mplus version 6.1 [27]. We fit latent class models with three to six classes at each time point, and computed the Vuong-Lo-Mendell-Rubin (VLMR) [28] and bootstrap likelihood ratio tests (BLRT) [29] and compared the Bayesian Information Criterion (BIC) [30] to decide on the number of classes that best fit the data [31]. We then conducted the latent transition analyses (LTA) using baseline and 6-month follow-up data. While we did examine the class structure in the 3-month follow-up data, we did not include the 3-month data in the LTA model. To assess the consistency of class structure over time, models with measurement thresholds constrained to be equal over time were compared with models allowing thresholds to vary, using the Satorra-Bentler Chi square difference test based on log-likelihood values and scaling correction factors obtained with the MLR estimator in Mplus [32]; see http://www.statmodel.com/chidiff.shtml. Finally, we added the intervention effect to the model as a known class variable, and compared a model with equal transition slopes across intervention arm (i.e. group main effect only) to a model with unequal transition slopes; that is, we tested the moderating effect of intervention arm on the multinomial regression of follow-up class on baseline class (see Figure $\mathrm{S} 1$, in Supplementary Material).

The probabilities of risk class membership at follow-up were further analyzed in Stata 12 using generalized linear models (glm procedure), specifying a binomial distribution and logit link function, and robust (sandwich) variance estimator. Predictors included intervention arm, most likely class at baseline, and their interaction. Contrasts were computed for the effect of intervention arm within risk class.

\section{Results}

\section{Sample Demographics}

The sample of DUIT participants who completed at least one follow-up interview $(N=712)$ was $65 \%$ male, $63 \%$ non-Hispanic White, $17 \%$ Hispanic, and $20 \%$ other race/ ethnicity. The mean age was 24, ranging from 15 to 30 years. Forty percent reported being homeless at some point in six months before baseline and $17 \%$ reported spending some time in jail during that period. Sexual behaviors in the past six months at baseline are shown in Table 2.
Table 2 Baseline sexual behavior past 6 months

\begin{tabular}{|c|c|c|}
\hline Measure & $\begin{array}{l}\text { Male } \\
N=466 \\
(\%)\end{array}$ & $\begin{array}{l}\text { Female } \\
N=246 \\
(\%)\end{array}$ \\
\hline \multicolumn{3}{|l|}{ Steady female partners } \\
\hline One & 51.2 & 11.1 \\
\hline More than one & 25.4 & 3.7 \\
\hline \multicolumn{3}{|l|}{ Casual female partners } \\
\hline One & 26.1 & 5.4 \\
\hline More than one & 26.3 & 3.3 \\
\hline \multicolumn{3}{|l|}{ Steady male partners } \\
\hline One & 4.0 & 66.8 \\
\hline More than one & 3.6 & 19.3 \\
\hline \multicolumn{3}{|l|}{ Casual male partners } \\
\hline One & 2.7 & 17.4 \\
\hline More than one & 4.9 & 25.6 \\
\hline Gave money or drugs for sex & 6.7 & 3.3 \\
\hline Received money or drugs for sex & 10.5 & 22.8 \\
\hline Unprotected sex with trade partners & 7.5 & 6.5 \\
\hline Unprotected vaginal sex, main partner & 60.7 & 73.2 \\
\hline $\begin{array}{l}\text { Unprotected heterosexual anal sex, main } \\
\text { partner }\end{array}$ & 20.2 & 20.7 \\
\hline $\begin{array}{l}\text { Unprotected vaginal sex, other steady } \\
\text { partners }\end{array}$ & 13.7 & 11.4 \\
\hline Unprotected vaginal sex, casual partners & 27.3 & 19.1 \\
\hline $\begin{array}{l}\text { Unprotected heterosexual anal sex, other } \\
\text { steady partners }\end{array}$ & 5.8 & 0.4 \\
\hline $\begin{array}{l}\text { Unprotected heterosexual anal sex, casual } \\
\text { partners }\end{array}$ & 10.5 & 6.5 \\
\hline $\begin{array}{l}\text { Unprotected anal sex, main male partner } \\
\text { (MSM) }\end{array}$ & 1.7 & NA \\
\hline $\begin{array}{l}\text { Unprotected anal sex, other steady male } \\
\text { partners (MSM) }\end{array}$ & 0.4 & NA \\
\hline $\begin{array}{l}\text { Unprotected anal sex, casual male partners } \\
\text { (MSM) }\end{array}$ & 2.4 & NA \\
\hline
\end{tabular}

\section{Male Sexual Risk Behavior}

In the latent class analyses of baseline data, the BIC pointed to a model with five classes, and the BLRT indicated significant improvement in fit compared to the four class model $($ BLRT $(12)=79.91, p<0.0001)$. The five classes included (1) a low risk group comprised of men who reported no unprotected sex (includes not sexually active) (28\%); (2) men who had unprotected sex with a main female partner only (30\%); (3) men who had unprotected sex with main and other female partners (29\%); (4) a high-risk group including men who have sex with men and women, and men who engaged in sex trade (6\%); and (5) men who have sex with men or engage in sex trade, and have low probability of unprotected sex with women $(7 \%)$. 
We then estimated a latent transition model with five classes. Although the class structure was invariant over time, the thresholds for the fifth class were changed slightly in the LTA model compared to the LCA model, now indicating no unprotected sex with women in this class. The class size shrunk from 7 to $4 \%$, and few men transitioned into or out of this class. Consequently, since the estimates for this class would have low reliability, we decided to exclude men who had sex with men only $(N=13)$ from the sample, and re-estimated the latent class models. The BIC and the VLMR likelihood ratio tests (see Table S1 in Supplementary Material) indicated that a 4-class solution fit best at each time point. We proceeded to estimate a latent transition model with four classes, and tested for non-invariance of measurement thresholds over time. The Satorra-Bentler LRT was non-significant $(\operatorname{TRd}(11)=11.97, p=0.37)$, indicating that the invariant model was adequate, i.e. that the class structure did not vary significantly between baseline and 6-month follow-up. Tables S2 and S3 in the Supplementary Material present subject characteristics associated with latent classes at baseline, and item probabilities associated with the LTA model.

\section{Intervention Effects}

We then added intervention arm as a known class variable, and tested the effect of the intervention by comparing a model with equal transition slopes across intervention arm to a model with unequal transition slopes (i.e., with time by arm interaction). The likelihood-ratio test was significant $(\operatorname{TRd}(9)=17.59, p=0.04)$, indicating that the intervention effect varied across classes. This model had an entropy value of 0.891, indicating good classification quality. Based on the posterior probabilities, the prevalence of the "low-risk" class increased from $28 \%$ at baseline to $47 \%$ at follow-up, while the prevalence of the "multiple female partner" class decreased from 32 to $20 \%$. The "main only" class prevalence was $29 \%$ at baseline, and $24 \%$ at follow-up, while the "high-risk" class comprised $11 \%$ of the sample at baseline, and $8 \%$ at follow-up. The transition probabilities from this model are shown in Table 3. The diagonal values include participants who remained in the same class at both time points. For example, the probability of a low-risk participant remaining in the low-risk class was $77 \%$ in the control arm and $90 \%$ in the PEI arm. The off-diagonal values represent transitions across classes. For example, in the control arm, the probability of a high-risk participant transitioning to the low-risk class was $32 \%$, and in the PEI arm the probability was $31 \%$.

The results of the generalized linear model analyses on the posterior probabilities of the outcome classes are shown in Table 4. The intervention arm by baseline risk class interaction effect was significant in three of the four models. In the analysis of the low-risk class probabilities, the overall interaction effect was non-significant; there was a trend for baseline low-risk class $\left(\mathrm{chi}^{2}=3.06, p=0.08\right)$, such that PEI participants were more likely to remain in this class $(88 \%)$ compared to "low-risk" participants in the control condition $(77 \%)$.

In the analysis of the "main only" class probabilities for men, baseline "low risk" participants in the PEI arm were significantly less likely to transition to this class than those in the control group ( 1 vs. $10 \%, \mathrm{OR}=0.10,95 \% \mathrm{CI}$ 0.03-0.31), and PEI participants in the "multiple female partners" risk group were significantly more likely to transition to the main only class ( 26 vs. $14 \%, \mathrm{OR}=2.16$, $95 \%$ CI 1.01-4.61). There was also a trend for the "highrisk" class, with $24 \%$ of PEI participants making this transition compared to $8 \%$ of control participants $(\mathrm{OR}=3.58,95 \%$ CI $0.88-14.54)$.

The analysis of the "multiple female partners" class found that PEI participants in the two higher risk classes had reduced odds of this outcome ("high risk" $2 \%$ vs. $6 \%$, OR $=0.09,95 \%$ CI 0.02-0.35); "multiple female partners" (31 vs. $49 \%, \mathrm{OR}=0.46,95 \%$ CI $0.25-0.87$ ). For the "high risk" outcome class, "low risk" PEI participants were less likely to transition to this class (0.1 vs. $5 \%, \mathrm{OR}=0.01,95 \%$ CI $0.003-0.08$ ).

Table 3 Unadjusted posterior probabilities of class membership at follow-up by baseline class and intervention arm, Men $(N=453)$

\begin{tabular}{|c|c|c|c|c|c|c|c|c|c|}
\hline \multirow[t]{2}{*}{ Baseline class $^{\mathrm{a}}$} & \multicolumn{4}{|l|}{ Control } & \multicolumn{4}{|l|}{ PEI } & \multirow[t]{2}{*}{$N$} \\
\hline & $\begin{array}{l}\text { Low-risk } \\
(\%)\end{array}$ & $\begin{array}{l}\text { Main } \\
\text { only }(\%)\end{array}$ & $\begin{array}{l}\text { Mult } \\
\text { fem (\%) }\end{array}$ & $\begin{array}{l}\text { High-risk } \\
(\%)\end{array}$ & $\begin{array}{l}\text { Low-risk } \\
(\%)\end{array}$ & $\begin{array}{l}\text { Main } \\
\text { only (\%) }\end{array}$ & $\begin{array}{l}\text { Mult } \\
\text { fem }(\%)\end{array}$ & $\begin{array}{l}\text { High-risk } \\
(\%)\end{array}$ & \\
\hline Low-risk & 77 & 12 & 8 & 3 & 90 & 0 & 10 & 0 & 133 \\
\hline Main only & 29 & 53 & 13 & 5 & 32 & 49 & 18 & 1 & 134 \\
\hline $\begin{array}{r}\text { Multiple } \\
\text { female }\end{array}$ & 32 & 15 & 47 & 5 & 39 & 25 & 31 & 5 & 137 \\
\hline High-risk & 32 & 9 & 14 & 45 & 31 & 24 & 0 & 45 & 49 \\
\hline
\end{tabular}

${ }^{a}$ Most likely class based on posterior probabilities 
Table 4 Predicted probabilities and contrasts, generalized linear model analysis, adjusted for age, race/ethnicity, and city (men)

\begin{tabular}{|c|c|c|c|c|c|c|c|c|}
\hline Outcome & \multicolumn{4}{|c|}{ Pred. Prob. } & \multicolumn{2}{|c|}{$95 \%$ Conf. Int. } & \multirow[t]{2}{*}{$\operatorname{chi}^{2}$} & \multirow[t]{2}{*}{$p$} \\
\hline & Control & PEI & OR & Std Err & LL & UL & & \\
\hline \multicolumn{9}{|l|}{ Low risk } \\
\hline Low risk & 0.77 & 0.88 & 2.12 & 0.91 & 0.91 & 4.94 & 3.06 & 0.080 \\
\hline Main only & 0.28 & 0.32 & 1.23 & 0.42 & 0.63 & 2.42 & 0.37 & 0.544 \\
\hline Mult female & 0.32 & 0.35 & 1.14 & 0.39 & 0.58 & 2.24 & 0.15 & 0.695 \\
\hline High risk & 0.35 & 0.37 & 1.09 & 0.63 & 0.36 & 3.37 & 0.02 & 0.876 \\
\hline Joint $(\mathrm{df}=4)$ & & & & & & & 3.58 & 0.467 \\
\hline \multicolumn{9}{|l|}{ Main only } \\
\hline Low risk & 0.10 & 0.01 & 0.10 & 0.06 & 0.03 & 0.31 & 14.98 & 0.000 \\
\hline Main only & 0.57 & 0.49 & 0.70 & 0.23 & 0.37 & 1.32 & 1.21 & 0.272 \\
\hline Mult female & 0.14 & 0.26 & 2.16 & 0.84 & 1.01 & 4.61 & 3.92 & 0.048 \\
\hline High risk & 0.08 & 0.24 & 3.58 & 2.56 & 0.88 & 14.54 & 3.18 & 0.074 \\
\hline Joint $(\mathrm{df}=4)$ & & & & & & & 23.23 & 0.0001 \\
\hline \multicolumn{9}{|l|}{ Multi female } \\
\hline Low risk & 0.08 & 0.10 & 1.39 & 0.73 & 0.50 & 3.87 & 0.4 & 0.529 \\
\hline Main only & 0.11 & 0.17 & 1.59 & 0.68 & 0.69 & 3.67 & 1.16 & 0.281 \\
\hline Mult female & 0.49 & 0.31 & 0.46 & 0.15 & 0.25 & 0.87 & 5.8 & 0.016 \\
\hline High risk & 0.16 & 0.02 & 0.09 & 0.06 & 0.02 & 0.35 & 11.76 & 0.001 \\
\hline Joint $(\mathrm{df}=4)$ & & & & & & & 19.11 & 0.001 \\
\hline \multicolumn{9}{|l|}{ High risk } \\
\hline Low risk & 0.05 & 0.00 & 0.01 & 0.01 & 0.00 & 0.08 & 23.66 & 0.000 \\
\hline Main only & 0.04 & 0.02 & 0.51 & 0.43 & 0.10 & 2.67 & 0.63 & 0.429 \\
\hline Mult female & 0.05 & 0.08 & 1.63 & 0.97 & 0.51 & 5.24 & 0.68 & 0.409 \\
\hline High risk & 0.34 & 0.31 & 0.86 & 0.57 & 0.23 & 3.17 & 0.05 & 0.821 \\
\hline Joint $(\mathrm{df}=4)$ & & & & & & & 25.52 & 0.000 \\
\hline
\end{tabular}

${ }^{a}$ Most likely class based on posterior probabilities

To summarize the effect of the intervention on the higher risk classes, we collapsed these two classes into one group, summed the probabilities for the two lower risk outcomes, and conducted a generalized linear model analysis of this total. Male PEI participants in the higher risk classes combined were significantly more likely $(p=0.025)$ than those in the control group to transition to either the "low risk" or "main only" class $(\mathrm{OR}=1.86$, $95 \%$ CI 1.08-3.21).

\section{Female Sexual Risk Behavior}

The BIC pointed to the 3-class model as the best-fitting model for both baseline and follow-up data (see Table S1 in Supplementary Material). The VLMR LRT also indicated a 3-class model at baseline, but suggested a 4-class model at 6-month follow-up. The 3-class model at both time-points identified (1) a low-risk class comprised of women who were not sexually active or had only one partner, and had either no unprotected sex or unprotected sex with a main partner only, (2) women who had more than one partner, and did not engage in trade sex, and (3) a high-risk class of women who engaged in trade sex. We proceeded to fit the latent transition model with three classes. Although there was similarity of the classes over time, there was also noticeable variability in the thresholds of several indicators. However, the likelihood ratio test for an invariant 3-class model compared to a non-invariant 3 -class model indicated that the invariant model had adequate fit (TRd $(24)=23.57, p=0.49)$. Tables S2 and S4 in the Supplementary Material present subject characteristics associated with latent classes at baseline, and item probabilities associated with the LTA model.

\section{Intervention Effects}

Again, we added intervention arm as a known class, and tested the effect of the intervention by comparing a model with equal transition slopes across intervention arm to a model with unequal transition slopes. The likelihood-ratio test was not significant $(\operatorname{TRd}(4)=1.67, p=0.80)$, indicating that the intervention effect did not vary across 
Table 5 Unadjusted posterior probabilities of class membership at follow-up by baseline class and intervention arm, women $(N=246)$

\begin{tabular}{|c|c|c|c|c|c|c|c|}
\hline \multirow[t]{2}{*}{ Baseline class $^{\mathrm{a}}$} & \multicolumn{3}{|l|}{ Control } & \multicolumn{3}{|l|}{ PEI } & \multirow[t]{2}{*}{$N$} \\
\hline & Low risk $(\%)$ & Multiple partners $(\%)$ & Trade sex $(\%)$ & Low risk $(\%)$ & Multiple partners (\%) & Trade sex $(\%)$ & \\
\hline Low risk & 67 & 29 & 4 & 70 & 27 & 3 & 122 \\
\hline Multiple partners & 49 & 31 & 20 & 43 & 46 & 11 & 73 \\
\hline Trade sex & 40 & 31 & 29 & 41 & 26 & 33 & 51 \\
\hline
\end{tabular}

${ }^{a}$ Most likely class based on posterior probabilities

classes. Overall, the prevalence of the "low-risk" class based on posterior probabilities increased from $50 \%$ at baseline to $56 \%$ at follow-up, while the "high-risk" class decreased from 21 to $13 \%$. The prevalence of the "multiple partners" class remained steady at $30 \%$ baseline and $31 \%$ at follow-up. The transition probabilities from this model are shown in Table 5. The generalized linear model analysis of outcome probabilities also found no significant differences between intervention arms for women.

\section{Discussion}

The results of the latent transition analysis suggest that the DUIT PEI had an effect on the sexual risk behavior of young male IDUs other than those who were in a monogamous relationship or who used condoms outside of their main relationship. Among men in this "main only" class, about $30 \%$ transitioned to the "low risk" class at follow-up regardless of intervention arm. Men in the PEI condition who were engaging in unprotected sex with multiple partners and other risky sexual behavior at baseline were more likely than those in the control group at follow-up to have transitioned to the "main only" classapparently reducing their sexual risk behavior by restricting unprotected sexual activity to one main partner. At the same time, men in the PEI condition who were not engaging in unprotected sex at baseline were less likely than those in the control group at follow-up to have transitioned to the "main only" class, apparently being more likely to use condoms in a new relationship, or to continue to use condoms with their main partner. In a similar study, Latkin et al. [33] found that in a network-oriented HIV prevention intervention based on social identity theory and peer outreach, experimental compared with control group participants were more likely to report increased condom use with casual sex partners, but not with main partners.

The absence of an intervention effect on sexual risk behavior among women may reflect the lack of genderspecific content in this program. Comprehensive reviews of the effects of HIV prevention and intervention programs have found that women benefit from programs that are specifically directed toward women, and that include a focus on relationship and negotiation skills [34-37]. Research has demonstrated the importance of addressing issues of gender norms, relationship power, sexual coercion, and negotiation of safer sex for reducing HIV risk behavior among women [38-40]. While the intervention was designed to be equally relevant to women and men, and included exercises to help women negotiate condom use with male partners, issues of relationship power and intimate partner violence (not dealt with directly) could have made it more difficult for women in the study to adopt new behaviors.

While HIV prevention interventions with IDUs have shown success in reducing injection-related HIV risk behavior, research into their effectiveness in limiting sexual transmission has been less promising. The bulk of existing research on intervention effectiveness has used analysis techniques that treat the sample as a homogeneous group, and assess behavioral outcomes with one-dimensional measures (e.g. number of unprotected sex acts); even when the measures are specific (e.g., number of unprotected sex acts with casual partners), they are assessed one at a time. However, sexual risk behavior is multi-dimensional, and is comprised of various combinations of behaviors (i.e., oral sex, anal sex, vaginal sex), partner types (i.e., casual, steady, exchange), and use of preventive measures (i.e., condom use). Participants exhibit different combinations of risk behaviors, and interventions may affect patterns of behavior in ways that one-dimensional measures do not capture. For example, in this study, less than half of the men reported unprotected sex with casual partners at baseline. When we consider this, it is not surprising that the initial analysis [23] did not find a significant intervention effect. A more nuanced analysis strategy is needed to assess changes on multiple dimensions. In this analysis we used latent class analysis to identify classes of sexual risk behavior, and then investigated the effect of the PEI intervention on the probability that young IDUs transitioned in and out of these classes. This type of analysis is well-suited for capturing change in complex multi-dimensional behavior. 
Limitations

Seventeen percent of the DUIT sample was lost to followup. Post-hoc analyses indicated that these participants were somewhat more likely to report lower risk sexual behavior at baseline compared to those who completed a follow-up interview. However, as reported previously [23], these participants were distributed equally across trial arm.

The smaller sample size of women, as well as the smaller proportion of non-sexually active women, may have resulted in a less satisfactory solution. Fewer than $6 \%$ of women in the DUIT sample reported no sexual activity at baseline, compared to $18.5 \%$ of men. At the 6-month follow-up, $15.8 \%$ of women and $32.6 \%$ of men reported no sexual activity. Women who did not have sex were classified together with women who had unprotected sex with a main partner only, while men who did not have sex were classified together with men who always used condoms.

\section{Conclusions}

This supplemental analysis of data from the DUIT study revealed that the PEI was at least partially effective in reducing sexual risk behavior among men, in contrast to the original analysis that found no effect. The PEI had an effect on men's sexual behavior, reducing the likelihood of unprotected sex with a main partner among men who did not engage in unprotected sex at baseline, and reducing the likelihood of unprotected sex with non-main partners among men who engaged in risky sexual behavior at baseline. The absence of an effect among women participants highlights the need for additional activities to impact sexual risk among women. While mixture modeling should not replace univariate outcome analyses, using latent classes to model the multi-dimensional aspects of sexual risk behavior may capture changes in sexual risk behavior that would otherwise be undetected.

Acknowledgments This study was supported by a Grant from the National Institute on Drug Abuse, R01 DA031584. The CIDUS-3/ DUIT intervention trial was supported by a cooperative agreement from the Centers for Disease Control and Prevention U64/ CCU317662, U64/CCU517656, U64/CCU917655, U64/CCU217659, U64/CCU017615; Institutional Review Board no. CDC-NCHSTP2934. The findings and conclusions in this report are those of the authors and do not necessarily represent the views of the National Institute on Drug Abuse or the Centers for Disease Control and Prevention. The DUIT Study Group includes the following people: Steffanie Strathdee, Elizabeth Golub, Marie Bailey-Kloch and Karen Yen-Hobelman (Baltimore); Lawrence Ouellet, Susan Bailey and Joyce Fitzgerald (Chicago); Sharon Hudson, Peter Kerndt and Karla Wagner (Los Angeles); Mary Latka, David Vlahov and Farzana Kapadia (New York); Holly Hagan, Hanne Thiede, Nadine Snyder and Jennifer V. Campbell (Seattle); and Richard Garfein, David Purcell, Ian Williams, Paige Ingram and Andrea Swartzendruber
(CDC). We thank Dr. Katie Witkiewitz for her expert assistance with the analysis.

Open Access This article is distributed under the terms of the Creative Commons Attribution License which permits any use, distribution, and reproduction in any medium, provided the original author(s) and the source are credited.

\section{References}

1. Doherty MC, Garfein RS, Monterroso E, Brown D, Vlahov D. Correlates of HIV infection among young adult short-term injection drug users. AIDS. 2000;14(6):717-26.

2. Hagan H, Perlman DC, Des Jarlais DC. Sexual risk and HIV infection among drug users in New York City: a pilot study. Subst Use Misuse. 2011;46(2/3):201-7. doi:10(3109/10826084).

3. Huo D, Ouellet LJ. Needle exchange and sexual risk behaviors among a cohort of injection drug users in Chicago, Illinois. Sex Transm Dis. 2009;36(1):35-40.

4. Kral AH, Bluthenthal RN, Lorvick J, Gee L, Bacchetti P, Edlin BR. Sexual transmission of HIV-1 among injection drug users in San Francisco, USA: risk-factor analysis. Lancet. 2001;357(9266):1397-401.

5. Li J, Liu H, Li J, Luo J, Des Jarlais D, Koram N. Role of sexual transmission of HIV among young noninjection and injection opiate users: a respondent-driven sampling study. Sex Transm Dis. 2011;38(12):1161-6. doi:10.1097/OLQ.0b013e3182315772.

6. Santibanez S, Garfein R, Swartzendruber A, Purcell D, Paxton L, Greenberg A. Update and overview of practical epidemiologic aspects of HIV/AIDS among injection drug users in the United States. J Urban Health. 2006;83(1):86-100. doi:10.1007/s11524005-9009-2.

7. Somlai AM, Kelly JA, McAuliffe TL, Ksobiech K, Hackl KL. Predictors of HIV sexual risk behaviors in a community sample of injection drug-using men and women. AIDS Behav. 2003; 7(4):383-93.

8. Strathdee SA. HIV sexual transmission in the context of injection drug use: implications for interventions. Int J Drug Policy. 2003;14(1):79-81. doi:10.1016/S0955-3959(02)00211-6.

9. Strathdee SA, Sherman S. The role of sexual transmission of HIV infection among injection and non-injection drug users. J Urban Health. 2003;80(3):7-14. doi:10.1093/jurban/jtg078.

10. Wood E, Schachar J, Li K, Stoltz J-A, Shannon K, Miller C, et al. Sex trade involvement is associated with elevated HIV incidence among injection drug users in Vancouver. Addict Res Theor. 2007;15(3):321-5.

11. Bogart LM, Kral AH, Scott A, Anderson R, Flynn N, Gilbert ML, et al. Sexual risk among injection drug users recruited from syringe exchange programs in California. Sex Transm Dis. 2005;32(1):27-34.

12. Javanbakht M, Guerry S, Gorbach PM, Stirland A, Chien M, Anton $\mathrm{P}$, et al. Prevalence and correlates of heterosexual anal intercourse among clients attending public sexually transmitted disease clinics in Los Angeles County. Sex Transm Dis. 2010;37(6):369-76. doi:10.1097/OLQ.0b013e3181cbf77d.

13. Javanbakht M, Gorbach P, Stirland A, Chien M, Kerndt P, Guerry S. Prevalence and correlates of rectal chlamydia and gonorrhea among female clients at sexually transmitted disease clinics. Sex Transm Dis. 2012;39(12):917-22. doi:10.1097/OLQ.0b013e31826ae9a2.

14. Reynolds GL, Fisher DG, Napper LE, Fremming BW, Jansen MA. Heterosexual anal sex reported by women receiving HIV prevention services in Los Angeles County. Women's Health Issues. 2010;20(6):414-9. doi:10.1016/j.whi.2010.07.006. 
15. Risser JMH, Padgett P, Wolverton M, Risser WL. Relationship between heterosexual anal sex, injection drug use and HIV infection among black men and women. Int J STD AIDS. 2009;20(5):310-4. doi:10.1258/ijsa.2008.008394.

16. Mackesy-Amiti ME, McKirnan DJ, Ouellet LJ. Relationship characteristics associated with anal sex among female drug users. Sex Transm Dis. 2010;37(6):346-51. doi:10.1097/OLQ.0b013 e3181c71d61.

17. Howard DL, Latkin CA. A bridge over troubled waters: factors associated with non-injection drug users having injection drugusing sex partners. J Acquir Immune Defic Syndr. 2006;42(3): 325-30. doi:10.1097/01.qai.0000214819.88163.22.

18. Jenness SM, Neaigus A, Hagan H, Murrill CS, Wendel T. Heterosexual HIV and sexual partnerships between injection drug users and noninjection drug users. AIDS Patient Care STDS. 2010; 24(3):175-81. doi:10.1089/apc.2009.0227.

19. Johnson RA, Gerstein DR, Pach A, Cerbone FG, Brown J. HIV risk behaviors in African-American drug injector networks: implications of injection-partner mixing and partnership characteristics. Addiction. 2002;97(8):1011-24.

20. Rachlis B, Brouwer KC, Mills EJ, Hayes M, Kerr T, Hogg RS. Migration and transmission of blood-borne infections among injection drug users: understanding the epidemiologic bridge. Drug Alcohol Depend. 2007;90(2-3):107-19. doi:10.1016/j. drugalcdep.2007.03.014.

21. Semaan S, Des Jarlais DC, Sogolow E, Johnson WD, Hedges LV, Ramirez G, et al. A meta-analysis of the effect of HIV prevention interventions on the sex behaviors of drug users in the United States. J Acquir Immune Defic Syndr. 2002;30(Suppl 1):S73-93.

22. Brown BS, Beschner GM. Handbook on risk of AIDS: injection drug users and sexual partners. Westport: Greenwood Press; 1993.

23. Garfein RS, Golub ET, Greenberg AE, Hagan H, Hanson DL, Hudson SM, et al. A peer-education intervention to reduce injection risk behaviors for HIV and hepatitis $\mathrm{C}$ virus infection in young injection drug users. AIDS. 2007;21(14):1923-32. doi:10. 1097/QAD.0b013e32823f9066.

24. Mackesy-Amiti ME, Ouellet LJ, Golub ET, Hudson S, Hagan H, Garfein RS. Predictors and correlates of reduced frequency or cessation of injection drug use during a randomized HIV prevention intervention trial. Addiction. 2011;106(3):601-8. doi:10. 1111/j.1360-0443.2010.03251.x.

25. Garfein RS, Swartzendruber A, Ouellet LJ, Kapadia F, Hudson $\mathrm{SM}$, Thiede $\mathrm{H}$, et al. Methods to recruit and retain a cohort of young-adult injection drug users for the Third Collaborative Injection Drug Users Study/Drug Users Intervention Trial
(CIDUS III/DUIT). Drug Alcohol Depend. 2007;91(Supplement 1):S4-17. doi:10.1016/j.drugalcdep.2007.05.007.

26. Purcell DW, Garfein RS, Latka MH, Thiede H, Hudson S, Bonner $\mathrm{S}$, et al. Development, description, and acceptability of a smallgroup, behavioral intervention to prevent HIV and hepatitis $\mathrm{C}$ virus infections among young adult injection drug users. Drug Alcohol Depend. 2007;91(Supplement 1):S73-80.

27. MPlus [computer program]. Muthén \& Muthén; Ver. 6.1, 2010.

28. Lo Y, Mendell NR, Rubin DB. Testing the number of components in a normal mixture. Biometrika. 2001;88(3):767-78. doi:10.1093/ biomet/88.3.767.

29. McLachlan G, Peel D. Finite mixture models. New York: Wiley; 2000.

30. Schwartz R. Estimating the dimension of a model. The Ann Stat. 1978;6:461-4.

31. Nylund KL, Asparouhov T, Muthén BO. Deciding on the number of classes in latent class analysis and growth mixture modeling: a Monte Carlo simulation study. Struct Equ Model. 2007;14(4): 535-69. doi:10.1080/10705510701575396.

32. Satorra A, Bentler PM. A scaled difference Chi square test statistic for moment structure analysis. Online 3 Aug 1999 Available from: http://preprints.stat.ucla.edu/download.php?paper=260.

33. Latkin CA, Sherman S, Knowlton A. HIV prevention among drug users: outcome of a network-oriented peer outreach intervention. Health Psychol. 2003;22(4):332-9. doi:10.1037/0278-6133.22.4.332.

34. Ehrhardt AA, Exner TM. Prevention of sexual risk behavior for HIV infection with women. AIDS. 2000;14(Suppl 2):53-8.

35. Exner TM, Hoffman S, Dworkin SL, Ehrhardt AA. Beyond the male condom: the evolution of gender-specific HIV interventions for women. Annu Rev Sex Res. 2003;14:114-36.

36. Exner TM, Seal DW, Ehrhardt AA. A review of HIV interventions for at-risk women. AIDS Behav. 1997;1(2):93-124.

37. Prendergast ML, Urada D, Podus D. Meta-analysis of HIV riskreduction interventions within drug abuse treatment programs. J Consult Clin Psychol. 2001;69(3):389-405. doi:10.1037//0022006x.69.3.389.

38. Choi K-H, Bowleg L, Neilands TB. The effects of sexism, psychological distress, and difficult sexual situations on US women's sexual risk behaviors. AIDS Educ Prev. 2011;23(5):397-411. doi:10.1521/aeap.2011.23.5.397.

39. Wingood GM, DiClemente RJ. Application of the theory of gender and power to examine HIV-related exposures, risk factors, and effective interventions for women. Health Educ Behav. 2000;27(5):539-65.

40. Amaro H, Raj A. On the margin: power and women's HIV risk reduction strategies. Sex Roles. 2000;42(7-8):723-49. 